\title{
Molecular and seroepidemiological survey on Crimean- Congo Hemorrhagic Fever Virus in Northeast of Iran
}

\author{
Abedin Saghafipour ${ }^{1}$, Ahmad Mousazadeh-Mojarrad² ${ }^{2}$ Niloofar Arzamani ${ }^{3}$, Zakyeh Telmadarraiy ${ }^{4}$, \\ Rezvan Rajabzadeh ${ }^{5,2}$, Kourosh Arzamani*2
}

Received: 10 Oct 2017

Published: 13 May 2019

\begin{abstract}
Background: Crimean-Congo hemorrhagic fever (CCHF) is a prevalent tick-borne disease in different regions of Iran. This molecular and serologic study was performed to investigate the Crimean-Congo hemorrhagic fever virus (CCHFV) in collected ticks and in blood samples of some domestic animals in North Khorasan, Northeast of Iran.

Methods: In this cross sectional study, 136 blood samples from domestic animals (sheep, goats, and cows) collected in the Northeast region in Iran were examined using IgG ELISA assay. Ticks $(n=1478)$ were collected from sheep, goats, and cows. Out of all collected ticks, 62 specimens were investigated for CCHF virus genome using RT-PCR technique. The data were descriptively presented by median and $95 \%$ confidence interval (CI).

Results: CCHFV infection rate was $8.1 \%$ in studied ticks. Two species of ticks, Hy. anatolicum $(\mathrm{n}=3 ; 15 \%, 95 \%$ CI 9.41-20.59) and Rh. sanguineus $(\mathrm{n}=2 ; 6.9 \%, 95 \%$ CI $4.33-8.58)$, were infected with CCHFV genome and were probable vectors of CCHF virus in the area. Infection rate was $15.4 \%$ for CCHFV in tested domestic animals. Serologic tests detected CCHFV specific IgG antibodies in $16.2 \%$ (95\% CI 13.49-18.83) (99/16) and 19.2\% (95\% CI 13.26-25.20) (26/5) of sheep and goats, respectively.

Conclusion: The present study showed that domestic animals and ticks were infected with Crimean-Congo hemorrhagic fever virus and that the disease was endemic in North Khorasan province, Iran. However, further surveillance and prevention programs are recommended.
\end{abstract}

Keywords: Crimean-Congo hemorrhagic fever, Ticks, Molecular technique, Serological test, Iran

Conflicts of Interest: None declared

Funding: Vector-borne Diseases Research Center, North Khorasan University of Medical Sciences, Bojnurd, Iran

*This work has been published under CC BY-NC-SA 1.0 license.

Copyright $\odot$ Iran University of Medical Sciences

Cite this article as: Saghafipour A, Mousazadeh-Mojarrad A, Arzamani N, Telmadarraiy Z, Rajabzadeh R, Arzamani K. Molecular and seroepidemiological survey on Crimean-Congo Hemorrhagic Fever Virus in Northeast of Iran. Med J Islam Repub Iran. 2019 (13 May);33:41. https://doi.org/10.47176/mjiri.33.41

\section{Introduction}

Crimean-Congo hemorrhagic fever (CCHF) is a tickborne disease, and its causative agent belongs to Bunyaviridae family and Nairovirus genus (1). The disease was first seen in the island of Crimea, Russia, in 1944 and then similar cases were observed in Congo in 1956. In 1969 , it became clear that the cause of 2 diseases was a

\footnotetext{
Corresponding author: Dr Kourosh Arzamani, k.arzamani@nkums.ac.ir

1. Department of Public Health, Faculty of Health, Qom University of Medical Sciences, Qom, Iran

2. Vector-borne Diseases Research Center, North Khorasan University of Medical Sciences, Bojnurd, Iran

3. School of Medicine, Tehran University of Medical Sciences, Tehran, Iran

4. Department of Medical Entomology, School of Public Health, Tehran University of Medical Sciences, Tehran, Iran

5. Department of Epidemiology, Student Research Committee, Iran University of Medical Sciences, Tehran, Iran
}

virus, and thus the disease was called Crimean- Congo hemorrhagic fever (2). The sources of this virus in nature are wild rabbits and birds. Sheep, goats, cows and other domestic animals can also be sources of the virus. Ixodidae family, mostly Hyalomma genus, is the vectors of virus to humans. The virus is transmitted from eggs to

$\uparrow$ What is "already known" in this topic:

Crimean-Congo hemorrhagic fever (CCHF) is considered as a zoonotic and tick-borne disease and there are some foci of this disease in Iran.

\section{$\rightarrow$ What this article adds:}

It was found that domestic animals, such as sheep and goats, and some tick's species, such as Hy. anatolicum $(\mathrm{n}=3 ; 15 \%$, 95\% CI 9.41-20.59) and Rh. sanguineus $(\mathrm{n}=2 ; 6.9 \%, 95 \% \mathrm{CI}$ 4.33-8.58), were infected with Crimean-Congo hemorrhagic fever virus and the disease was endemic in North Khorasan province, Iran. 
mature ticks in consecutive generations of ticks. Animals as a source of virus become infected by the bite of infected sucking blood nymph and adult ticks. Animals play the role of a viral reservoir in nature and do not suffer from the disease and do not have clinical symptoms. Humans can get CCHF disease via the contact of their injured skin and the mucosa with blood and secretions of contaminated animals, the bite of infected ticks, and the nosocomial infection of CCHF among health care workers, such as medical and nursing staff (3). The incubation period for the CCHF virus varies based on the mode of the virus transmission. Commonly, incubation period following a tick bite ranges 1-3 days and 5-6 days after contact with infected blood, secretions, or tissues of infected animals (4). The onset of CCHF disease is sudden. Initial clinical symptoms of the disease include high fever, bad general condition, weakness, irritability, and headache, severe pain in the extremities and back, and anorexia. Vomiting, abdominal pain, and diarrhea are also observed in some cases. The hemorrhage phase of disease begins at the fifth day of the illness and lasts for 1-10 days. In severe and fatal cases, high volume bleeding from the nose, lungs, gums, uterus, and intestines are mentioned and often accompanied with liver damage. Ultimately, internal bleeding causes shock, pulmonary edema, and even death. The fatality rate of the disease is about $30 \%$ of the total patients (5). CCHF virus is widely observed among domestic and zoonotic animals, birds, and ticks throughout the world. The disease is reported as epidemic and sporadic forms in Europe, Mediterranean countries, Turkey, Iran, other Middle Eastern countries, and Arab states which border the Persian Gulf, Pakistan, and Saudi Arabia (3, 6, 7). According to previous studies conducted from 1999 onwards, numerous cases of CCHF have been reported as the epidemic form in many areas of Iran, including Sistan $\&$ Baluchestan, Isfahan, and other regions. These cases were confirmed via paraclinical surveys $(6,8)$. This disease can be diagnosed via identifying CCHFV specific antibodies in humans and animals. These antibodies are IgM and IgG that can be detected by ELISA or immunofluorescence (9). Furthermore, polymerase chain reaction technique (PCR) has been applied successfully to detect $\mathrm{CCHF}$ virus genome in vectors, reservoir, and human hosts (10). The risk factors of this disease are as follow: endemic foci of this disease in many areas of Iran; high abundance of CCHF viremia; positive serology in animals, such as sheep and cow $(5,10,11,12)$; prevalence of animal husbandry in North Khorasan and its neighboring province of Razavi Khorasan (13) and Afghanistan and Tajikistan $(14,15)$. Thus, this molecular and seroepidemiological study was performed to reveal the epidemiological status of Crimean-Congo hemorrhagic fever virus in ruminants and ticks collected from Northeast of Iran bordering with Turkmenistan in 2013- 2017.

\section{Methods}

\section{Study sites}

This cross sectional study was conducted in North Khorasan province, northeast of Iran from 2013 to 2017. This province is located at $36^{\circ} 37^{\prime}-38^{\circ} 17^{\prime} \mathrm{N}$ latitudes and $55^{\circ} 53^{\prime}-58^{\circ} 20^{\prime}$ E longitudes, with an area of more than 28 $434 \mathrm{~km}^{2}$. The province is bordered by Turkmenistan in the north, Khorasan Razavi province in the east and southeast, Semnan province in the southwest, and Golestan province in the west (Fig. 1). North Khorasan province includes 8 counties with a population of 863092 . The province has desert and mountainous areas and receives about $250 \mathrm{~mm}$ of rainfall annually.

\section{Blood samples from domestic animals}

At first, permission was obtained from North Khorasan Office of Veterinary. Before the start of the study, the aim of the study was explained and the number of livestock in the province was determined by their species and habitat. Multistage sampling method was used to select domestic animals. According to the number of sites (villages) and number of livestock, 3-5 livestock were selected in each village and a checklist was filled for each. In total, 136 blood samples were taken via venoject from the jugular veins of the domestic animals (cows, sheep, and goats) Their historical data, including age of animals, gender, and region of habitat, were reported. Then, $10 \mathrm{~mL}$ blood was collected from every livestock. The samples were immediately taken to the laboratory of Vector-borne Diseases Research Center, North Khorasan University of Medical Sciences, and their serums were extracted. Each blood sample was placed in a micro-tube and kept in the Pasteur Institute in Tehran, Iran, at a temperature below $20^{\circ} \mathrm{C}$ until analysis.

\section{Serologic tests for detecting CCHFV specific IgG anti-} bodies

The serum samples were analyzed by specific ELISA to detect IgG. IgG detection involved coating the ELISA plates with mouse hyper-immune ascetic fluid (diluted at 1:1000) in phosphate-buffered saline (PBS $1 \times$ ) and incubating them overnight at $4^{\circ} \mathrm{C}$. Following the washing step,

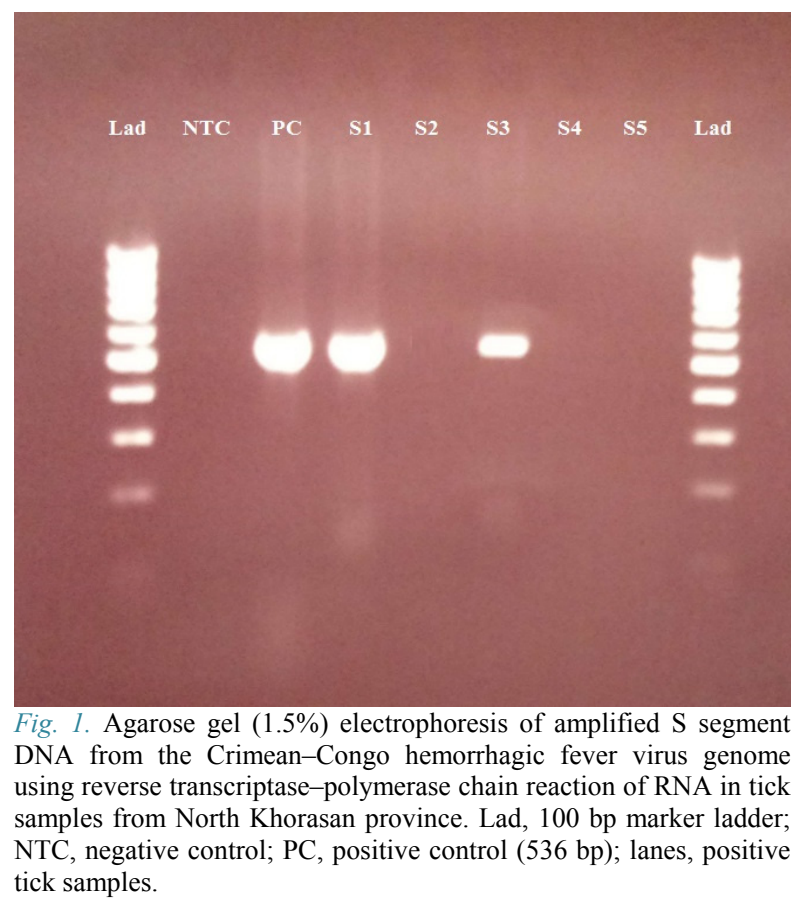


the native or recombinant antigen (diluted at 1:500) in PBS containing 0.5\% Tween (PBST) and 3\% skim milk (PBSTM), was added and the plates were incubated for 3 hours at $37^{\circ} \mathrm{C}$. Serum diluted at $1: 100$ in PBSTM was added and the plates were incubated for 1 hour at $37^{\circ} \mathrm{C}$. Peroxidase-labeled antianimal immunoglobulin diluted at 1:1000 in PBSTM was added and the plates were incubated for 1 hour at $37^{\circ} \mathrm{C}$. The plates were washed 3 times with PBST after each incubation. Finally, hydrogen peroxide and 3,3',5,5'-tetramethyl benzidine (TMB) were added and the plates were incubated for 15 minutes at room temperature. The enzymatic reaction was stopped by the addition of $4 \mathrm{~N}$ sulfuric acid. The plates were read by an ELISA reader (Anthos 2020) at $450 \mathrm{~nm}$ (16).

\section{Ticks collection}

During 2013-2017, the ticks were collected from infested ruminants, including cows, sheep and goats. Additionally, some specimens were collected from turtles, rodents, and hedgehogs. The tick samples were collected from 53 different areas in the province. Multistage sampling method was used for selecting domestic animals. According to the number of sites and number of livestock living in these regions, in each village, 10-30 livestock were selected. Specimen collection was performed in accordance with the procedures approved by the Ethical Committee of North Khorasan University of Medical Sciences. Specimens were performed by examining the whole body, including, ears, abdomen, tail, perianal regions, milk gland area, and back of the animals. Collected ticks were placed in separate dry and labeled vials and transferred to laboratory of Vector Borne Diseases Research Center, North Khorasan University of Medical Sciences. All specimens were identified based on morphological characteristics and the keys given by Janbakhsh (1956) and Hoogsteraal (1956) in the laboratory of Medical Entomology, Tehran University of Medical Sciences. All statistical analyses were done by excel software 2010 and SPSS 16.

\section{RNA extraction}

The collected ticks were washed twice with phosphatebuffered saline (PBS), pH 7.4, separately and were crushed using a mortar and pestle in $200 \mu \mathrm{L}$ of PBS. Total RNA of ticks was extracted using RNeasy plus Mini Kits (Cat. No. 74136, Qiagen, Venlo, The Netherlands), according to the manufacturer's protocol. The extracted total RNA was stored at $-70^{\circ} \mathrm{C}$ until further analysis (17).
Reverse transcriptase-polymerase chain reaction (RTPCR)

To amplify the genomic RNA of CCHFV, OneStep RTPCR Kit (Cat. No. 210212, Qiagen) was used. All components were mixed to prepare the master mix as follow: RNase free water $28(\mathrm{~L}), 5 \times$ Qiagen OneStep RT-PCR Buffer $(10 \mu \mathrm{L})$, dNTP Mix (containing $10 \mathrm{~mm}$ of each dNTP) $(2 \mu \mathrm{L})$, Iran-F2 primer 5'-TGGACACCTTCA CAAACTC-3' $(10 \mu \mathrm{M}) 1 \mu \mathrm{L}$, Iran-R3 5'-GACAATTCCC TACACC-3'primer $(10 \mu \mathrm{M}) 1 \mu \mathrm{L}$, enzyme mix $(2 \mu \mathrm{L})$, and RNase inhibitor $0.5 \mu \mathrm{L}$ (Cat. No. 10777-019, Invitrogen, Thermo Fisher Scientific, Waltham, MA, USA). Finally, $5 \mu \mathrm{L}$ of template was added to the tube and the thermal-cycler program was started. The cycling parameters were as follow: reverse transcription for 30 minutes at $50^{\circ} \mathrm{C}$, for 15 minutes at $95^{\circ} \mathrm{C}$ as hot start, 35 cycles of 30 seconds of denaturation at $95^{\circ} \mathrm{C}, 30$ seconds of annealing at $50^{\circ} \mathrm{C}, 45$ seconds of elongation at $72^{\circ} \mathrm{C}$, with final elongation of 5 minutes at $72^{\circ} \mathrm{C}$.

\section{Product analysis}

In this study, $5 \mu \mathrm{L}$ of PCR amplicons on $1.5 \%$ agarose gel was examined using gel loading buffer with DNA stain (Cat. No. PCR-255-bl, Jena Bioscience, Germany) and Gene ruler 100 bp ladder (Cat. No.SM0242, Thermo Scientific) as a molecular-weight size marker.

\section{Statistical analysis}

The data were descriptively presented by median and $95 \%$ confidence interval (CI) using SPSS software, version 16

\section{Results}

In this study, 515 (55.2\%) out of 933 inspected sheep, goat, and cow were infested with ticks. A total of 1478 ticks (770 males and 708 females) were collected. The identified tick specimens belonged to hard ticks group and soft ticks. CCHFV infection rate was $8.1 \%$ in studied ticks. Two species of ticks, Hy. anatolicum $(\mathrm{n}=3 ; 15 \%$, 95\% CI 9.41-20.59) and Rh. sanguineus ( $\mathrm{n}=2 ; 6.9 \%$, 95\%CI 4.33-8.58), were infected with CCHFV genome. $A$. persicus and $A$. reflexus belonged to soft ticks and were not infected with CCHF virus (Table 1).

In addition, CCHFV infection tested domestic animals were $15.4 \%(95 \% \mathrm{CI}, 9.3-21.5)$. Serologic tests detected CCHFV specific IgG antibodies in $16.2 \%$ (95\%CI, 8.9$23.5)(99 / 16)$ and $19.2 \%(95 \% \mathrm{CI}, 4.1-34.3)(26 / 5)$ of sheep and goats, respectively, while all serum specimens

Table 1. Molecular details of the tick species were collected and examined for the presence of CCHF virus genome, North Khorasan, Northeast of Iran

\begin{tabular}{|c|c|c|c|c|c|c|c|c|c|c|}
\hline \multirow[t]{3}{*}{ Species } & \multirow{2}{*}{\multicolumn{2}{|c|}{ Ticks }} & \multicolumn{8}{|c|}{ Infection status N (\%) } \\
\hline & & & \multicolumn{2}{|c|}{ Life cycle stage } & \multicolumn{2}{|c|}{ Gender } & \multicolumn{3}{|c|}{ Host type } & Total infection rate \\
\hline & $\mathrm{N}$ & $(\%)$ & Nymph & Adult & Male & Female & Cow & Sheep & Goat & N (\%,CI95\%) \\
\hline Hy. anatolicum & 20 & 32.25 & 1 & 2 & 3 & 0 & 2 & 1 & 0 & $3(15,9.41-20.59)$ \\
\hline Hy. marginatum & 4 & 6.45 & 0 & 0 & 0 & 0 & 0 & 0 & 0 & $0(0 \%)$ \\
\hline Hae. sulcata & 2 & 3.23 & 0 & 0 & 0 & 0 & 0 & 0 & 0 & $0(0 \%)$ \\
\hline Rh. sanguineus & 31 & 50.00 & 0 & 2 & 0 & 2 & 0 & 1 & 1 & $2(6.45,4.33-8.58)$ \\
\hline A. persicus & 2 & 3.23 & 0 & 0 & 0 & 0 & 0 & 0 & 0 & $0(0 \%)$ \\
\hline A. reflexus & 3 & 4.84 & 0 & 0 & 0 & 0 & 0 & 0 & 0 & $0(0 \%)$ \\
\hline Total & 62 & $(100)$ & 1 & 4 & 3 & 2 & 2 & 2 & 1 & $5(8.06,6.22-9.91)$ \\
\hline
\end{tabular}


gathered from cows were negative (Table 2) (Fig. 1).

Serologic positive livestock in all counties and ticks infected with CCHFV genome were identified in some counties (Fig. 2).

\section{Discussion}

Crimean-Congo hemorrhagic fever is an important zoonotic viral illness and some species of ticks are the main vectors of this disease. The domestic and wild animals as asymptomatic reservoirs and humans as sensitive hosts are epidemiologic elements to formation of the disease transmission cycle (18). Meanwhile, some species of birds are also surviving and distributing the CCHFV-infected ticks mechanically (19). Several factors are important in CCHF prevention and control, including surveillance system, awareness and having data about the fauna of the vectors and the reservoirs of CCHF disease, their contamination of CCHFV, and the status of virus transmission dynamics in nature (20). The disease is most commonly found in the Sub-Saharan African countries, Eastern Europe (Turkey, Ukraine, Romania), the Middle East (Iraq, Syria, Afghanistan, Pakistan, Iran) (21), India (22) and West China (23). The disease is prevalent in warm seasons from late March to late September (growth and reproduction time of ticks) (24). CCHF disease has been observed in 26 of the Iran's 31 provinces in endemic or sporadic forms, with the greatest number of patients in Sistan and Baluchestan, Esfahan, Fars, Khorasan, Tehran, and Khuzestan provinces (25). In the present study, a molecular and serologic study was designed to investigate CCHF virus genome in collected ticks and to examine domestic animals in villages and counties of North Khorasan, Northeast of Iran. In this study, CCHFV infection rate in tested ticks was found to be $8.1 \%$. Previous studies have indicated that the infection rate of CCHFV in different areas of Iran varied from $0.2 \%$ to $33.3 \%(1,26-39)$. In the present study, it was found that infected tick's species were Hy. anatolicum and $R h$. sanguineus. Previous studies showed that CCHFV infection rate in Hyalomma genus ticks ranged from $1.57 \%$ to $20 \%$ in Iran $(1,26-39)$. The infection rate of Rhipicephalus ticks was reported to be $1.8 \%$ to $55 \%$ in previous studies in Iran $(27,29,30,32,37)$. Therefore, it can be concluded that although Hyalomma ticks are usually introduced as the vectors of CCHF, this potential exists in other genera as well. Telmadarraiy et al reported the most frequent tick species positive for CCHF virus in Iran to be Hy. marginatum, Hy. dromedarii, Hy. anatolicum, Hy. Asiaticum, and Rh. sanguineus (40). In this study, CCHFV infection was detected in $15.4 \%$ of tested domestic animals. The results revealed that sheep and goats were serologically positive for CCHFV specific IgG antibodies. Meanwhile, all samples from cows were negative. The detection of virus has been reported frequently in domes-

Table 2. Crimean-Congo hemorrhagic fever virus (CCHFV) seroprevalence in domestic animals, North Khorasan, Northeast of Iran

\begin{tabular}{|c|c|c|c|c|c|}
\hline \multirow[t]{2}{*}{ County } & \multicolumn{3}{|c|}{ Animal } & \multirow{2}{*}{$\begin{array}{c}\text { Seroprevalence } \\
(\text { tested/+) } \\
(\%, \text { CI95\%) }\end{array}$} & \multirow[t]{2}{*}{ Assay } \\
\hline & $\begin{array}{c}\text { Cow } \\
\text { (tested } /+) \%\end{array}$ & $\begin{array}{c}\text { Sheep } \\
\text { (tested/+) \% }\end{array}$ & $\begin{array}{c}\text { Goat } \\
\text { (tested } /+) \%\end{array}$ & & \\
\hline Esfarayen & 0 & $22 / 5$ & $6 / 2$ & $(28 / 7)(25,15.39-30.06)$ & IgG ELISA \\
\hline Raz and Jargalan & $2 / 0$ & $7 / 2$ & $1 / 0$ & $(10 / 2)(20,13.45-43.69)$ & IgG ELISA \\
\hline Garmeh & 0 & $7 / 1$ & 0 & $(7 / 1)(14.28,5.21-23.35)$ & IgG ELISA \\
\hline Maneh and Samalqan & $6 / 0$ & $13 / 3$ & $3 / 0$ & $(22 / 3)(13.63,13.43-32.73)$ & IgG ELISA \\
\hline Shirvan & $2 / 0$ & $21 / 3$ & $8 / 1$ & $(31 / 4)(12.90,9.04-19.53)$ & IgG ELISA \\
\hline Jajarm & 0 & $8 / 0$ & $1 / 1$ & $(9 / 1) 0$ & IgG ELISA \\
\hline Bojnurd & $1 / 0$ & $13 / 1$ & $5 / 1$ & $(19 / 2)(10.53,6.29-14.76)$ & IgG ELISA \\
\hline Faruj & 0 & $8 / 1$ & $2 / 0$ & $(10 / 1)(10.00,4.42-15.58)$ & IgG ELISA \\
\hline Total & $(11 / 0) \quad 0.00 \%$ & $(99 / 16)(16.2,8.9-23.5)$ & $(26 / 5)(19.2,4.1-34.3)$ & $(136 / 21)(15.44,13.25-17.63)$ & IgG ELISA \\
\hline
\end{tabular}

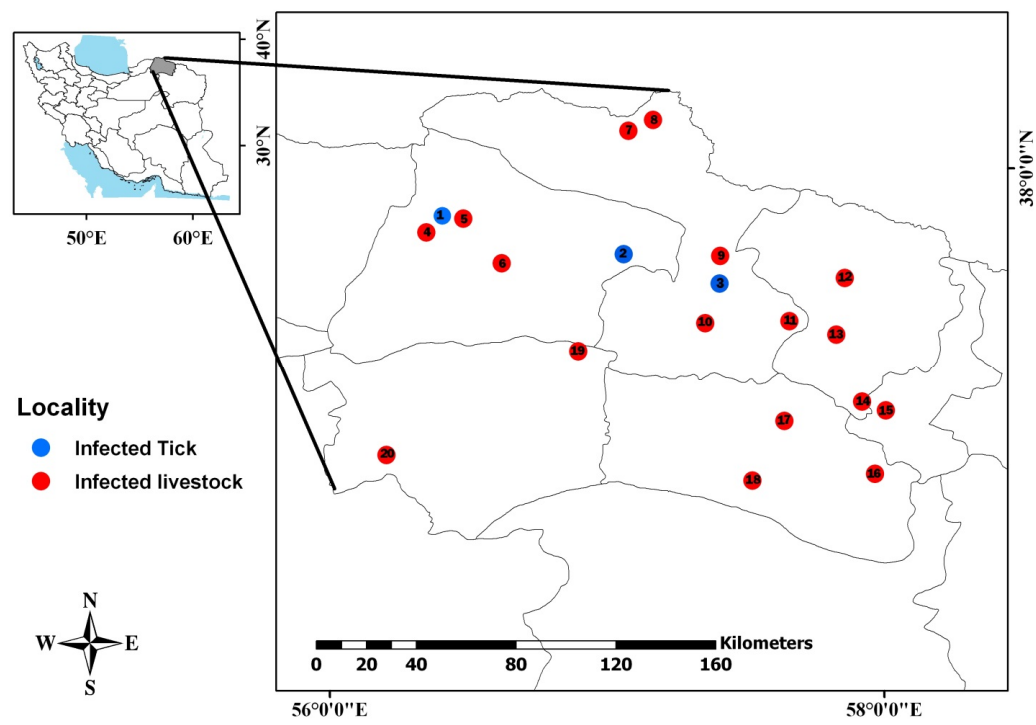

Fig. 2. Map of the study area and geographical locations of infected ticks and livestock. Collected from North Khorasan Province, north-east of Iran, 2013-2017. 
tic animals (for instance sheep, goats, camels, and cows) in different regions of Iran (40). This rate varied in other regions; for instance, in Khorasan province, $77.5 \%$ of sheep samples and $46 \%$ of goat samples were positive for CCHFV (41). Also, in Mazandaran province, 3.7\% of samples from sheep were positive for CCHFV (42).

\section{Conclusion}

The present study showed that domestic animals and ticks were infected with Crimean-Congo hemorrhagic fever virus and that the disease was endemic in North Khorasan province. However, the infection rate of $\mathrm{CCHF}$ virus in domestic animals and ticks were not highly prevalent in the province. It is recommended to have surveillance system and preventive strategies. Also, holding health education sessions for health staffs and people can be effective in reduction of the disease.

\section{Acknowledgments}

This article was part of a research approved at Vectorborne Diseases Research Center, North Khorasan University of Medical Sciences, Bojnurd, Iran (Project code: 93/762). We thank all participants from North Khorasan University of Medical Sciences and the staff at Pasteur Institute of Iran who sincerely helped us in conducting the study.

\section{Conflict of Interests}

The authors declare that they have no competing interests.

\section{References}

1. Telmadarraiy Z, Saghafipour A, Farzinnia B, Chinikar S. Molecular Detection of Crimean-Congo Hemorrhagic Fever Virus in Ticks in Qom Province, Iran, 2011-2012. Iran J Virol. 2012; 6(3):13-18.

2. Mardani M, Keshtkar-Jahromi M. Crimean- Congo Hemorrhagic Fever. Arch Iranian Med. 2007;10(2):204-214.

3. Sabbaghian H. Emerging and Reemerging Zoonotic Diseases. Iran J Epidemiol. 2006;1(3,4):1-9.

4. Whitehouse CA. Crimean-Congo hemorrhagic fever. Antiviral Res. 2004;64(3):145-160.

5. Saghafipour A, Norouzi M, Sheikholeslami N, Mostafavi R. Epidemiologic status of the patients with Crimean Congo Hemorrhagic Fever and its associated risk factors. J Mil Med. 2012;14(1):1-5.

6. Izadi S, Naieni KH, Madjdzadeh SR, Nadim A. CrimeanCongohemorrhagic fever in Sistan and Baluchestan province of Iran, a case-control study on epidemiological characteristics. Int J Infect Dis. 2004;8(5):299-306.

7. Khan AS, Maupin GO, Rollin PE, Noor AM, Shurie HH, Shalabi AG, et al. An outbreak of Crimean-Congo hrmorrhagic fever in the United Arab Emarates, 1944-1955. Am J Trop Med Hyg. 1997;57(5):519525.

8. Salehi H. A comparative study on the effect of ribaverin with and without IVIG (Intravenous imuneglobuliu) in treatment of Crimeancongo hemorrhagic Fever (CCHF). J Mazand Univ Med Sci. 2004; 14(43):33-39.

9. Ergonul O. Crimean-Congo hemorrhagic fever. Lancet Infect Dis. 2006;6(4):203-214. 9.

10. Atae Bi, Touluei HR, Chinikar S, Darvishi M, Jalali N, Izadi M, et al. Seroepidemiology of Crimean-Congo hemorrhagic fever in the local and imported sheep in Isfahan provience, Iran, 2002. Iran Clin Infect Dis. 2006;1(1):19-23.

11. Rodriguez LL, Maupin GO, Ksiazek TG, Rollin PE, Khan AS, Schwarz TF, et al. Molecular investigation of a multisource outbreak of Crimean-Congo hemorrhagic fever in the United Arab Emirates. Am J Trop Med Hyg. 1997;57(5):512-518.
12. Williams RJ, Al-Busaidy S, Mehta FR, Maupin GO, Wagoner KD, Al-Awaidy S, et al. Crimean-congo haemorrhagic fever: a seroepidemiological and tick survey in the Sultanate of Oman. Trop Med Int Health. 2000;5(2):99-106.

13. Lotfollahzadeh S, Nikbakht Boroujeni GR, Mokhber Dezfouli MR, Bokaei S. A serosurvey of Crimean-Congo haemorrhagic fever virus in dairy cattle in Iran. Zoonoses Public Health. 2011;58(1):54-9.

14. Chamberlain J, Atkinson B, Logue CH, Latham J, Newman ENC, Hewson R. Genome Sequence of Ex-Afghanistan Crimean-Congo Hemorrhagic Fever Virus SCT Strain, from an Imported United Kingdom Case in October 2012. Genome Announcements. 2013;1(3): e00161-13

15. Farida H, Tishkova, Evgeniya A. Belobrova, Matlyuba Valikhodzhaeva, et al. Crimean-Congo Hemorrhagic Fever in Tajikistan. Vector Borne Zoonotic Dis. 2012;12(9):722-726.

16. S Garcia S, Chinikar S, Coudrier D, Billecocq A, Hooshmand B, Crance JM, et al. Evaluation of a Crimean-Congo hemorrhagic fever virus recombinant antigen expressed by Semliki Forest suicide virus for IgM and IgG antibody detection in human and animal sera collected in Iran. J Clin Virol. 2006; 35:154-159.

17. Champour M, Chinikar S, Mohammadi G, Razmi G, Shah-Hosseini $\mathrm{N}$, Khakifirouz S, et al. Molecular epidemiology of Crimean-Congo hemorrhagic fever virus detected from ticks of one humped camels (Camelus dromedarius) population in northeastern Iran. J Parasit Dis. 2016; 40:110-5.

18. Mustafa ML, Ayazi E, Mohareb E, Yingst S, Zayed A, Rossi C, et al. Crimean-Congo haemorrhagic fever, Afghanistan, 2009. Emerg Infect Dis. 2011; 17:1940-1941.

19. Spengler JR, Bergeron É, Rollin PE. Seroepidemiological Studies of Crimean-Congo Hemorrhagic Fever Virus in Domestic and Wild Animals. PLoS Negl Trop Dis. 2016; 10(1): e0004210.

20. Tekin S, Bursali A, Mutluay N, Keskin A, Dundar E. CrimeanCongo hemorrhagic fever virus in various ixodid tick species from a highly endemic area. Vet Parasitol. 2012; 186:546-52.

21. Messina JP, Pigott DM, Golding N, Duda KA, Brownstein JS, Weiss $\mathrm{DJ}$, et al. The global distribution of Crimean-Congo hemorrhagic fever. Trans R Soc Trop Med Hyg.2015;109(8):503-513.

22. Patel AK, Patel KK, Mehta M, Parikh TM, Toshniwal H, Patel K. First Crimean-Congo hemorrhagic fever outbreak in India. J Assoc Physicians India. 2011; 59:585-9.

23. Xia H, Li P, Yang J, Pan L, Zhao J, Wang Z, et al. Epidemiological survey of Crimean-Congo hemorrhagic fever virus in Yunnan, China. Int J Infect Dis. 2011;15: e459-63.

24. Randolph SE. Dynamics of tick-borne disease systems: minor role of recent climate change. Rev Sci Tech. 2008 Aug;27(2):367-81.

25. Keshtkar-Jahromi M, Sajadi MM, Ansari H, Mardani M, HolakouieNaieni K. Crimean-Congo hemorrhagic fever in Iran. Antiviral Res. 2013 Oct;100(1):20-8

26. Shirani M, Asmar M, Chinikar S, Mirahmadi R, Piazak N, Mazaheri V. Detection of CCHF virus in soft ticks (Argasidae) by RT-PCR method. J Infect Dis Trop Med. 2004; 9:11-15.

27. Telmadarraiy Z, Davari A, Vatandoost H. Ruminant animal ticks and their role in CCHF transmission in Ghaen, south Khorasan Province, Iran during 2005. In ICOPA XI11th Inter Con Parasito. 2006 pp. $6-1$

28. Telmadarraiy Z, Chinikar S, Vatandoost H, Holakoui K, Faghihi F, Zarei Z, et al. P1044 Serology and immunological study on the infectivity of host animals and ticks (Ixodidae, Argasidae) to CCHF virus

in Ardabil Province, Iran. Int J Antimicrob Agents. 2007; 29: S280.

29. Telmadarraiy Z, Ghiasi SM, Moradi M, Vatandoost H, Eshraghian MR, Faghihi F, et al. A survey of Crimean-Congo haemorrhagic fever in livestock and ticks in Ardabil Province, Iran during 2004-2005. Scand J Infect Dis. 2010; 42(2): 137-141.

30. Moradi AR, Chinikar S, Oshaghi MA, Vatandoost H, HoulakouiNaeini K, Zahirnia AH, et al. Molecular detection of Crimean-Congo hemorrhagic fever (CCHF) virus in ticks (Ixodidae, Argasidae) of Hamedan Province, Iran. Biochem Cell Arch. 2008; 8:119-123.

31. Nasiri A, Telmadarraiy Z, Vatandoost H, Chinikar S, Moradi A, Oshaghi MA, et al. Tick infestation rate of sheep and their distribution in Abdanan county, Ilam Province, Iran, 2007-2008. J ArthropodBorne Dis. 2010; 4:56-60.

32. Tahmasebi F, Ghiasi SM, Mostafavi E, Moradi M, Piazak N, Mozafari A, et al. Molecular epidemiology of Crimean-Congo hemorrhagic fever virus genome isolated from ticks of Hamadan Province of 
Iran. J Vector Borne Dis. 2010; 47:211-216.

33. Salim-Abadi Y, Chinikar S, Telmadarraiy Z, Vatandoost H, Moradi M, Oshaghi MA, et al. Crimean-Congo hemorrhagic fever: a molecular survey on hard ticks (Ixodidae) in Yazd Province, Iran. Asian Pac J Trop Med. 2011; 4:61-63.

34. Chinikar S, Ghiasi SM, Naddaf S, Piazak N, Moradi M, Razavi MR, et al. Serological evaluation of Crimean-Congo hemorrhagic fever in humans with high-risk professions living in enzootic regions of Isfahan Province of Iran and genetic analysis of circulating strains. Vector Borne Zoonotic Dis. 2012; 12:733-738.

35. Fakoorziba MR, Golmohammadi P, Moradzadeh R, MoemenbellahFard MD, Azizi K, Davari B, et al. Reverse transcription PCR-based detection of Crimean-Congo hemorrhagic fever virus isolated from ticks of domestic ruminants in Kurdistan province of Iran. Vector Borne Zoonotic Dis. 2012;12(9):794-9

36. Sharifinia N, Rafinejad J, Hanafi-Bojd AA, Biglarian A, Chinikar S, Baniardalani M, et al. Knowledge and Attitudes of the Rural Population and Veterinary and Health Personnel Concerning Crimean-Congo Hemorrhagic Fever in Western Iran in 2012. Florida Entomol. 2013;96(3): 922- 928.

37. Karimi F. Determination of viral infection rate of hard ticks to Crimean- Congo hemorrhagic fever (CCHF) and their distribution pattern using Geographic Information System (GIS) in the Kashan District, Isfahan Province. Master of Science Medical Entomology. Teheran University of Medical Sciences, School of public Health and Institute of Public Health Research Department of Medical Entomology and Vector Control. 2013.

38. Mehravaran A, Moradi M, Telmadarraiy Z, Mostafavi E, Moradi AR, Khakifirouz S, et alS. Molecular detection of Crimean-Congo haemorrhagic fever (CCHF) virus in ticks from southeastern Iran. Ticks and Tick-borne Dis. 2013:35-38.

39. Champour M, Mohammadi GR, Chinikar S, Razmi GR, ShahHosseini N, Khakifirouz S, et al. Seroepidemiology of CrimeanCongo hemorrhagic fever virus in one-humped camels (Camelus dromedarius) population in northeast of Iran. J Vector Borne Dis. 2014; 51: 62-65.

40. Telmadarraiy Z, Chinikar S, Vatandoost H, Faghihi F, HosseiniChegeni A. Vectors of Crimean Congo Hemorrhagic Fever Virus in Iran. Journal of Arthropod-Borne Dis. 2015;9(2):137-147.

41. Chinikar S. Seroepidemiology of crimean-congo haemorrhagic fever in human and domestic animals in Iran by analyzing the quantities of specific IGM and IGG against the virus of the disease by ELISA method. J Veterin Organiz. 2003; 3:69-73.

42. Mostafavi E, Chinikar S, Esmaeili S, Bagheri Amiri F, Tabrizi AMA, Khakifirouz S. Seroepidemiological surveyof Crimean-Congo hemorrhagic fever among sheep in Mazandaran province, northern Iran. Vector Borne Zoonotic Dis. 2012;12(9):739-742. 